\title{
¿Cómo se Armoniza el Derecho Mercantil Internacional?
}

\author{
José Alexander Ávila Vallecillo*
}

\section{Resumen}

Desde sus inicios, la costumbre y usos mercantiles han sido considerados equívocamente como referentes únicos en cuanto a contratación mercantil internacional se refiere.

No obstante, existe en la actualidad una pluralidad de normas tendientes a regular de forma específica las relaciones comerciales y por ende la resolución de conflictos suscitados entre los nacionales de un estado en particular.

En cuanto a su aplicación normativa, la doctrina y jurisprudencia internacional han dotado al derecho mercantil internacional de un variado compendio jurídico cuya aplicación práctica está supeditada a la materia, naturaleza, obligatoriedad y su contenido contractual.

Es así, que surgen las Normas Integrantes del Derecho Uniforme del Comercio Internacional (DUCl), ante la necesidad de armonizar y uniformizar internacionalmente esas pautas jurídicas aplicables al caso concreto y cuyo objetivo principal en disciplinar las relaciones comerciales de orden privado y de carácter obligacional.

Con relación a su fuente de producción, son varias las instituciones dedicadas a la elaboración de compendios jurídicos, la nacionalidad de las partes contratantes y el lugar de celebración o cumplimiento de obligaciones mercantiles, constituyen el pilar fundamental en los mismos.

El artículo pretende describir, resumir y definir el conjunto de normas jurídicas que integran el sistema armonizador de leyes mercantiles internacionales, incluyendo tratados, convenios, usos y prácticas, reglamentos, estatutos, recopilaciones, clausulados, guías jurídicas, etc.

Palabras Clave: Derecho Mercantil Internacional, Derecho uniforme, principios, fuentes, armonización, convención.

\section{Abstract}

Since its inception, custom and commercial uses have been mistakenly considered as only reference regarding international commercial contracts are concerned.

However, there is currently a plurality of rules aimed at regulating in a specific trade relations and hence the resolution of conflicts arising between nationals of a particular state.

In terms of policy implementation, doctrine and international jurisprudence have given the international trade law a varied legal compendium whose practical application is subject to the material nature and its contractual obligation content.

Thus arise the members of the Uniform Rules on International Trade Law (DUCl), given the need to harmonize and standardize these international legal standards applicable to the particular case and whose main purpose in disciplining trade relations of a private nature and obligational character.

With regard to its production source, several institutions dedicated to the development of legal compendia, the nationality of the contracting parties and the venue or compliance with commercial obligations, constitute the mainstay in them.

The article intends to describe, summarize and define the set of legal rules that make up the harmonizing system of international commercial law, including treaties, conventions, customs and practices, regulations, statutes, collections, legal guides, etc.

Keywords: Uniform law, legal principles, sources, harmonization convention, International Trade Law.

\footnotetext{
* Abogado, Magister en Derecho con énfasis en Derecho Mercantil, Contratos y Negocios Internacionales. Docente en la Facultad de Ciencias Jurídicas, Departamento de Derecho Privado, Universidad Nacional Autónoma de Honduras. Instituto de Investigación Jurídica, Edificio 5, Planta baja, e-mail: jaavhn@yahoo.com
} 


\section{INTRODUCCIÓN}

En un mundo globalizado donde las industrias, el comercio, las finanzas y economías amplían sus fronteras, se torna justo y necesario establecer estructuras jurídicas internacionales que permitan el desarrollo y mejoramiento económico entre los estados y sus particulares.

Bajo esa perspectiva, resulta ineludible la creación de organismos 0 entes reguladores que se encarguen de la administración, cooperación y supervisión de las negociaciones políticas y comerciales suscitadas entre los estados y sus particulares con el propósito de resolver armónicamente aquellos conflictos o diferencias que se susciten en el desarrollo de esos procesos comerciales entre los países involucrados.

Aspectos referentes a la aplicación e implementación de leyes uniformes, tecnologías de la información, obligaciones contractuales, acuerdos y convenios comerciales, han sido entre otros, temas sujetos a múltiples y variadas discusiones en el ámbito universal, especialmente los que giran en torno a la Armonización y Uniformización de leyes adoptadas en referencia a la contratación Mercantil internacional y su perfeccionamiento.

Verbigracia, el Derecho contractual europeo, ha sido expuesto a muchos cambios e innovaciones con respecto a la aspiración de unificar y armonizar en un solo compendio de leyes o normas aspectos de común aplicación a sus estado miembros, y nos referimos al proyecto denominado "marco común de referencia" el cual representa un real y novedoso desafío continental, sobre todo en lo que respecta a temas vinculados a la regulación de obligaciones y contratos internacionales, cuyo objetivo principal es la consolidación de un código civil unificado.

\section{METODOLOGÍA}

En cuanto a su aplicación normativa, tanto la doctrina como la jurisprudencia internacional, han concedido al derecho mercantil internacional un variado compendio jurídico cuya aplicación práctica está supeditada a la materia, naturaleza, obligatoriedad y contenido contractual.

Por ende, la metodología utilizada en el presente artículo es de tipología descriptiva, analítica y explicativa, por cuanto fue más allá de una escueta lectura normativa y doctrinaria. Se buscó por el contrario, realizar un especial análisis sobre aquellos razonamientos convergentes entre la doctrina y la costumbre internacional, donde subyacen los argumentos más fundamentales con relación a la temática.

Así las cosas, el artículo pretende describir, resumir y definir el conjunto de normas jurídicas que integran el sistema armonizador de leyes mercantiles internacionales, incluyendo tratados, convenios, usos y prácticas, reglamentos, estatutos, recopilaciones, clausulados, guías jurídicas que rigen la contratación mercantil internacional desde la perspectiva del derecho continental

\section{ANTECEDENTES HISTÓRICOS}

Históricamente, el derecho de los negocios internacionales o Derecho Mercantil codificado surgió en respuesta a los diferentes cambios sobrevenidos en la normativa de un modelo codificador tradicional; la aparición de leyes especiales, la unificación del régimen de obligaciones civiles y comerciales permitieron la aparición de un nuevo orden económico internacional.

Según Fernández (2009) el ius mercatorum se originó en un momento en que aún no se había consolidado la fórmula política del estado, sin embargo, existía en Europa un referente común (ius commune) el cual era incapaz de brindar una respuesta jurídica a las necesidades prácticas del comercio internacional.

De acuerdo al autor, fue en el siglo XIII, en el seno de las sociedades comerciales de la era medieval donde originalmente se presentó un conflicto de estatutos, donde coexistía una dualidad de ordenamientos jurídicos, es decir, por una parte, el Derecho Canónico ventilaba cuestiones relativas a la validez del matrimonio, y por otra, la Lex Mercatoria armonizaba las relaciones privadas de carácter internacional entre particulares. 
Aunque en sus inicios dicha Ley tuvo un alcance limitado, ésta fue adquiriendo confiabilidad y prestigio entre los comerciantes medievales al ser utilizada como guía legislativa en los Tribunales consulares de la época, dando origen a su internacionalización y cuya aplicación jurídica se mantiene vigente hoy en día. Por tanto, la Lex Mercatoria constituye uno de los precedentes jurídicos más antiguos en el Derecho Mercantil Internacional.

\section{CARACTÉRISTICAS DEL DERECHO MERCANTIL INTERNACIONAL}

Previo a establecer rasgos particulares vinculados al derecho mercantil internacional, se torna absolutamente necesario establecer un concepto jurídico que nos permita identificar rasgos característicos que rodean a esta normativa jurídica, cuya pretensión es la de armonizar el Derecho Mercantil Internacional y que actualmente forman parte de las normas integrantes del derecho uniforme del comercio Internacional (DUCl).

Para Fernández de la Gándara y Calvo Caravaca (1995), El Derecho Mercantil Internacional puede definirse como:

"...el conjunto de normas del ordenamiento jurídico que regulan los problemas específicos del tráfico económico internacional de las empresas o, si se prefiere una definición más explícita, como un Derecho fundamentalmente privado - especial por razón de las exigencias del tráfico económico internacional organizado bajo forma de empresa" (P.65)

Partiendo de la premisa anterior, podemos decir entonces que el Derecho Mercantil Internacional, posee los caracteres jurídicos siguientes:
a)Internacionalidad.
b)Uniformidad.
c)Normativa jurídica de influencia privatista.

En cierto modo, las contrataciones mercantiles adquieren su carácter de internacional desde el preciso instante en que las partes contratantes ratifican su contenido en países diferentes al de su residencia habitual, cuya observancia ha de realizarse interestatalmente y donde la nacionalidad de los sujetos intervinientes difiere una de otra.

Con relación a la internacionalidad, el Dr. Illezcas (2003) afirma que el Derecho Mercantil está mezclado por un conjunto de reglas internacionales de carácter especial; su origen y naturaleza jurídica está supeditada a las normas que integran el derecho uniforme. Por tanto su fundamento radica en la disciplina del comercio internacional y las relaciones contractuales celebradas entre sujetos que poseen sus establecimientos comerciales en estados diferentes.

En tanto, la uniformidad hace referencia al procedimiento aplicable a las controversias o conflictos que se suscitan entre los nacionales de los estados contratantes, cuyo argumento constitutivo descansa en el establecimiento de una norma única, válida y transfronteriza capaz de resolver cualquier demanda jurídica de naturaleza privada.

Fernández Rozas (2009), sostiene firmemente que:

"Ante la inexistencia hoy por hoy, de un Derecho de los Negocios Internacionales común a todos los estados, tendremos que combinar de distintas fuentes de producción Jurídica, de origen institucional, convencional e interno. A partir de aquí, puede definirse este ordenamiento como el conjunto de normas jurídicas que rigen las operaciones comerciales realizadas por operadores jurídicos privados cuyos intereses se sitúan en estados diferentes (p.47).

En alusión a su carácter jurídico privado o ius privatista, las reglas del Derecho Mercantil Internacional se rigen por un marcado proceso de privatización de sus normas, en otras palabras, se inspira en el principio de libertad de contratación o libertad de pacto donde las partes poseen libertad absoluta para celebrar un contrato y determinar su contenido interno. En consecuencia, el origen del Derecho Mercantil Internacional se encuentra inspirado en acuerdos, tratados o convenciones multilaterales, los cuales son adoptados producto 
de una convención, cumbre presidencial o pactos comunitarios, las diferencias y conflictos que se suscitan entre los nacionales de esos estados se dirimen a través del Derecho internacional privado.

Es tanta la influencia del ius privatum que autores como Illezcas (2003), resaltan en sus obras que el derecho público no forma parte integrante de las normas del Derecho uniforme del comercio Internacional (DUCI en delante), en vista que el Derecho Mercantil Internacional:

“...no aspira a interferir en la soberanía económica de los estados; más bien aspiran a que la soberanía de los estados les permita gobernar las concretas conductas privadas y libres de sus ciudadanos individuales, personas físicas y jurídicas, los cuales se reclaman el Derecho Uniforme " (p. 36)

En otras palabras, el Derecho Mercantil Internacional se encuentra altamente influenciado por un ordenamiento jurídicoprivado, donde el derecho público no tiene cabida, al ser producto de las relaciones comerciales que se suscitan entre los particulares, que pueden ser incluso de diferentes Estados, pero cobijados con una normativa la cual establece las reglas de negociación, conllevando al principio general del derecho denominado el de la seguridad jurídica.

\section{NATURALEZA Y FORMULACIÓN DE LAS NOR- MAS INTEGRANTES DEL DERECHO UNIFOR- ME DEL COMERCIO INTERNACIONAL}

El origen constitutivo de las normas integrantes o fuentes de producción jurídica comercial, están encaminadas a unificar y armonizar el comercio internacional entre los estados, cuyos reclamos y demandas se hacen evidentes ante la celebración de variados y múltiples contratos y de negocios comerciales internacionales.

Así entonces, el derecho uniforme se configura según Fernández (2009) como la técnica de reglamentación óptima para las transacciones comerciales internacionales, en la medida en que garantiza como ninguna otra la seguridad jurí- dica y la previsibilidad de los operadores económicos (p.63).

En tal sentido, realizaremos un estudio sistemático tomando como referente jurídico las fuentes, el origen y la naturaleza jurídica de leyes aplicables al caso concreto, desde una perspectiva comercial internacional.

Podemos decir entonces que el derecho mercantil internacional se armoniza y formula de la manera siguiente:

\section{A) EN CUANTO A SU ORIGEN O NATURALEZA JURÍDICA:}

Tal como lo hemos señalado en apartados anteriores y por su naturaleza jurídica, los contratos y negocios internacionales poseen un carácter transnacional, la función de los legisladores estatales se torna infructuosa al no satisfacer las respuestas jurídicas que las partes en conflicto demandan ante una diferencia específica.

Bajo ese esquema, el jurista Fernández (2009) se atreve a aseverar que:

"El comercio internacional comprende al mundo entero como campo de actuación y queda, portanto, bajo la esfera de intervención de organismos internacionales, de carácter universal o regional; por ello el gobierno regulador de esta realidad jurídica de naturaleza transnacional coarta la posibilidad del legislador estatal de determinar con entera libertad las respuestas jurídicas a estas transacciones de acuerdo con su propia concepción del mercado" (p. 25)

A razón de lo anterior y ante la imposibilidad de los estados para regular el Derecho Mercantil Internacional, surge la necesidad de armonizar o uniformar el Derecho de los Negocios internacionales cuya validez y aceptación por parte de los estados o los particulares, poseen un alto reconocimiento y aceptación entre los mismos. 
En cuanto a su origen y naturaleza jurídica, las fuentes que integran el derecho uniforme podrían estar categorizadas en la forma siguiente:

Figura \# 1

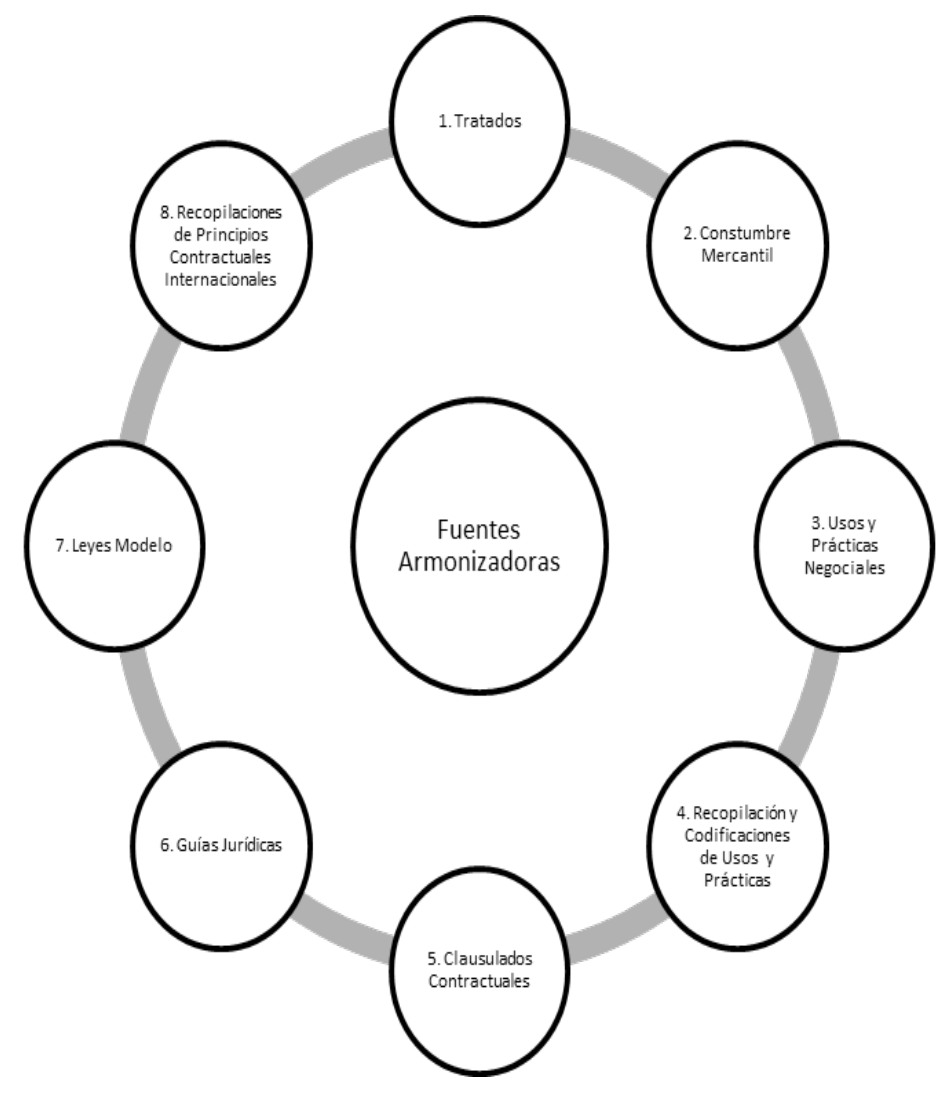

\section{1.- LOS TRATADOS}

Los tratados constituyen por excelencia, arquetipos primigenios con relación al conjunto de normas integrantes y armonizadoras del derecho mercantil internacional, sin embargo y debido a su carácter multilateral, esta fuente jurídica presenta ventajas e inconvenientes como cauce de positivización en el ámbito jurídico nacional.

La doctrina estima que los Tratados despliegan múltiples ventajas al proporcionar certeza sobre la materia aunada entre los estados contratantes, a contrario sensu, éstos suelen presentar inconvenientes ante la rigidez que toda codificación puede traer consigo y por las dificultades de transposición que un texto ofrece en cada sistema jurídico nacional (Fernández Rosas, Arenas y De Miguel Ascencio, 2009, p. 65).

Así las cosas y aunque en sentido prima facie (primera apariencia), los tratados poseen una característica eminentemente pública, éstos adhieren un objetivo más limitado al no intervenir en la soberanía económica de un estado, sino más bien a regular las conductas privadas entre los particulares de esos países. A razón de esto es que podemos aseverar que dichos compendios internacionales constituyen originalmente la principal fuente de todo estatuto jurídicointernacional.

\section{2.- LA CUMBRE MERCANTIL}

Históricamente, los usos y prácticas medievales observadas en plazas comerciales de la época solían ofrecer respuestas empíricas a los constantes problemas que se suscitaban entre comerciantes o mercaderes del momento.

Los conflictos eran resueltos al amparo de hábitos reiterados de conducta emitidos por Tribunales comerciales (universitas mercatorum), quienes abrigados bajo la sombra de la costumbre mercantil, justificaban sus resoluciones basados en pautas razonables, ciertas y notorias. En contexto y desde una perspectiva internacional, la costumbre mercantil hoy en día, debe satisfacer una práctica negocial para ser considerada como norma consuetudinaria, misma que debe ser calificada desde dos escenarios diferentes, es decir, desde la amplitud de su conocimiento y desde la regularidad en su observancia en el tráfico comercial de que se trate. Illezcas (2003).

\section{3.- USOS Y PRÁCTICAS NEGOCIALES}

Dentro del marco jurídico de las normas que integran el derecho uniforme en materia mercantil internacional, Ortiz y Perales (2003) afirman que a los usos y prácticas negociales se les atribuyen valores normativos a precedente contractuales al punto de colmar lagunas existentes en un determinado contrato sujeto a interpretación (p. 53)

Un claro ejemplo de éstos, lo constituye los INCOMTERMS 
2000, donde los usos y prácticas incorporadas a los contratos obligan a las partes por cualquier uso en que hayan convenido y por cualquier práctica establecida a lo interno de ellas (artículo 9.1)

Una desventaja que presentan estas prácticas es que suelen carecer de generalidad geográfica comercial y de observancia con relación a la costumbre internacional.

\section{4.- LAS RECOPILACIONES $Y$ CODIFICACIONES DE USOS Y PRÁCTICAS}

Las reglas y usos uniformes en materia de créditos documentarios de 1993, constituyen uno de los textos por excelencia que integran y armonizan el derecho mercantil internacional.

Según Ortiz y Perales (2003) dichos estatutos deben poseer un requisito esencialmente válido, es decir la libertad de las partes para incorporarlos a sus contratos mercantiles:

"...puesto que las recopilaciones, no son condiciones generales de los contratos ni la sumisión a las mismas de una determinada relación negocial ya que dependen de su incorporación al contrato en mención......Son usos y prácticas formuladas de modo abstracto y general cuya aplicación a cada caso depende de la voluntad de las partes" (p.55)

\section{5.- CLAUSULADOS CONTRACTUALES}

Estos clausulados representan un potente elemento de armonización del derecho comercial internacional. Los empresarios y sus asociaciones internacionales son las entidades encargadas de formular las condiciones generales aplicables a los contratos en los que más frecuentemente intervienen aquellos como parte, bien a modo de recomendación o a modo de compromiso corporativo. (Perales, 2003, pag. 55)

Cuestiones relativas a pólizas de seguro deben ser relacionadas en estos clausulados, como también los formularios referentes a los contratos de transportes de mercaderías y por ende de sus derivaciones legales. Entre los organismos formuladores de este compendio jurídico se encuentran la United Nations Conference on Trade and Development (UNCTAD), Cámara de Comercio Internacional (CCl) y la Federation Intenacionale des Associations de transitaires et Assimilés (FIATA).

\section{6.- GUÍAS JURÍDICAS:}

De acuerdo con Fernández Rosas (2009), estos instrumentos jurídicos de uniformización internacional son elaborados con la finalidad de establecer un cuadro jurídico apropiado para que las partes en un contrato internacional fijen de común acuerdo el contenido obligacional del mismo.

Por su parte, Ortiz y Perales (2003) afirman que las guías jurídicas detectan:

“...para el género del contrato al que se refieren, las cuestiones y las materias de mayor importancia sobre las que las partes han de convenir si se pretende concertar un contrato completo; en segundo lugar, ofrecen una solución convencional para dichos problemas desde una posición justa $y$ equitativa, insertando incluso un ejemplo literal de la cláusula en ciertas ocasiones" (p.57)

Pese a lo anterior, de las herramientas que tiende a armonizar el derecho mercantil internacional, las guías jurídicas representan el más débil estatuto normativo de integran a las DUCl.

\section{7.- LEYES MODELO}

En analogía con los tratados o convenios internacionales, las leyes modelos representan para los ciudadanos de un estado contratante, las guías jurídicas por excelencia.

Cabe señalar que el factor de transposición de un tratado 0 Ley modelo al derecho interno juega aspecto muy preponderante y sensible a la vez, puesto que al carecer de obligatoriedad, éstas no constriñen a sus estados miembros a incorporarlas internamente, el Tratado de Roma constituye un fiel ejemplo de este cometido. 


\section{8.- RECOPILACIONES DE PRINCIPIOS CON- TRACTUALES INTERNACIONALES}

El Instituto Internacional para la Unificación del Derecho Privado (UNIDROIT), constituye el organismo mandante en cuanto a la recopilación, identificación y formulación de principios universalmente aplicables a los contratos internacionales.

De acuerdo con Ortiz y Perales (2003), las recopilaciones de principios contractuales poseen finalidades concretas:

“...desde un objetivo regulador hasta un mero afán de ayuda a la redacción de textos contractuales, tales recopilaciones por el momento poseen para cada relación concreta las fuerza de obligar que las partes de la propia relación hayan querido atribuirle expresamente en el caso concreto" (P. 60)

Asimismo, existen otros referentes normativos que son inmediatos a la compraventa internacional de mercaderías, que revisten y a la vez consolidan al derecho comercial uniforme, entre los cuales podemos mencionar, la Prescripción, las garantías a Primera Demanda (Convención de las Naciones Unidas sobre Garantías Independientes y Cartas de Crédito Contingentes CNUGICCC), El Leasing y el Factoring Internacional.

\section{B) EN CUANTO A SU FUENTE DE PRODUCCIÓN JURÍDICA INSTITUCIONAL:}

En cuanto a armonización institucional se refiere y con el transcurrir de los años, diversas entidades y países vinculados al tema de contratación mercantil internacional, han venido estructurando una serie de instrumentos jurídicos encaminados a proveer un marco normativo aplicable según la norma y caso concreto.

En tal sentido, la doctrina nos permite afirmar que se ha venido "construyendo un conjunto de normas jurídicas de muy diversa índole, procedencia y formulación, destinadas a disciplinar el comercio internacional y, de modo particular, los aspectos jurídico-privados de las relaciones comerciales internacionales" (Ortiz Rafael y Viscasillas Pilar, 2003, p. 27)

Dicho autores afirman que, durante ese proceso de construcción o edificación sistemática se fue generando una clasificación dualista de normas, "las primeras que tienden a permitir o meramente facilitar el comercio internacional y reglas, las segundas, cuyo objeto relevante es disciplinar las relaciones comerciales internacionales individualmente consideradas en sus aspectos obligacionales y de derecho privado" (p. 28.)

La fuente estatal constituye en otros, una de las principales fuentes generadoras del derecho uniforme del comercio internacional, quienes actúan bajo el impulso de las "agencias formuladoras, definidas éstas, como organismos internacionales dotados de la más variada configuración jurídica, los cuales antes de convocar a una conferencia diplomática en la que los estados ejercitan su poder creador de normas uniformes, han preparado el proyecto de convención objeto de discusión y posterior firma"(ibid, p. 27)

En definitiva, los organismos encargados de llevar a cabo tareas preparatorias en cuanto a la formulación de normas en el campo mercantil internacional son:

- La Comisión de las Naciones Unidas para el Derecho Mercantil Internacional (CNUDMI o UNCITRAL)

- El Instituto para la Unificación del Derecho Privado (UNIDROIT).

- La Conferencia de la Haya de Derecho Internacional Privado.

- Cámara de Comercio Internacional.

La Comisión de las Naciones Unidas para el Derecho Mercantil Internacional (CNUDMI o UNCITRAL), es una Comisión especializada y permanente de la Asamblea General de las Naciones Unidas dependiente de la sexta comisión, asuntos jurídicos de la propia asamblea y que, por lo tanto forma parte del sistema de las Naciones Unidas.

Para Arrollo (2010) La Uncitral "constituye una de las principales fuentes generadoras de derecho comercial internacio- 
nal y, al mismo tiempo, la que mejor refleja el peso del sector privado en la elaboración de sus instrumentos, tanto del hard law como de soft law (p.60), no obstante en el reglamento de la Asamblea General de las Naciones Unidas no hay ninguna disposición sobre la forma de elaborar instrumentos normativos, que es la actividad propia de la CNUDMI.

Otra institución armonizadora del derecho comercial Internacional y por ende continental, lo constituye el Instituto para la unificación del Derecho Privado (UNIDROIT), dicha entidad es un organismo de carácter internacional, "creado precisamente con el objetivo de promover la armonización y unificación del Derecho Privado Internacional, teniendo como punto de partida la creciente liberalización del comercio y el proceso de integración económica" (Oviedo Albán, 2010, p.38).

No obstante, la aplicación de los principios Unidroit, ha sido objeto de muchas controversias y disimilitudes con respecto al derecho interno de los estados, tal es así que, Kleinheisterkamp (2009), estima que "...frente al derecho nacional y los Tribunales estatales no han recibido mucha atención hasta el presente, sin embargo, la nueva dimensión del rol de los principios como fuente de interpretación del derecho nacional, más allá de los tratados del derecho uniforme integrados en el orden jurídico nacional, solo fue incluida en su nueva edición del ahora en el parágrafo $7^{\circ}$ del preámbulo: Estos principios pueden ser utilizados para interpretar o complementar el Derecho Nacional" (p. 177).

De acuerdo con Perales Viscasillas (2007), en Europa, los principios sobre contratos comerciales internacionales elaborados por la Unidroit o Instituto Roma constituyen uno de los esfuerzos más apreciables por uniformar el derecho substantivo aplicable a los contratos comerciales internacionales, enmarcándose, junto con otros textos de carácter internacional, en el llamado Derecho Uniforme del Comercio Internacional, cuyo fin es disminuir las incertidumbres acerca del derecho aplicable, lo que evidentemente acrecentará la confianza entre las partes contratantes (p.157-161).

Aparejado a los Principios Unidroit y ahora en una nueva iniciativa restringida al derecho europeo, destaca la labor realizada por la Comisión del "Derecho europeo de contratos" o
Comisión Lando, están sirviendo como base para fundar, en su caso una futura Unificación del derecho contractual europeo, aunque toda vía no es clara la forma en que finalmente se conseguirá dicha unificación (Viscasillas, 2007, p. 158).

En el 2003 dicha comisión publicó el llamado plan de acción que consiste en una serie de medidas que englobarían en el llamado Marco Común de Referencia, cuyos eslabones de la cadena, por ahora, están representados por la comunicación de la Comisión al Parlamento y al Consejo Europeo.

Para Arroyo (2010), La Conferencia de la Haya de Derecho Internacional Privado, constituye otra de las entidades dedicadas a la armonización, unificación y reglamentación del Derecho Comercial, esta institución ya que:

"...no solo se ha ocupado directamente, desde una perspectiva conflictual, de temas tales como la intermediación de valores, los contratos de compraventa y agencia, o el trust, sino que ahora mismo está trabajando en la ley aplicable en materia de contratos internacionales con el propósito declarado de promover la autonomía de la voluntad (p.67)".

Actualmente, más que hábitos amparados en la costumbre apoyadas en la frecuencia de conductas, se promueve la formulación de reglas Uniformes en forma escrita cuya vigencia se fundamenta no tanto a la condición de usos de comercio, sino en la incorporación expresa de las mismas a un pacto escrito, surgiendo de esta manera el Stablishment económico-jurídico internacional, la cual constituye la más alta manifestación de organismos arbitrales internacionales, como ser, la Cámara de Comercio Internacional cuya sede actual es París, Francia.

\section{C) EN CUANTO A SU APLICACIÓN JURÍDICA:}

La naturaleza privada de la normativa del derecho mercantil se evidencia en cada una de las resoluciones emitidas por la jurisprudencia internacional, asimismo, los pronunciamientos de litigios comerciales están siendo fundamentados al amparo de leyes, acuerdos, principios y códigos con denominación específica, tomando como referente jurídico, la materia, na- 
turaleza y validez de los contratos mercantiles.

Ahora bien, cabe preguntarse, ¿cuál es la ley aplicable a cada caso concreto?, ¿Qué normativa se utilizará para determinar la validez de un contrato mercantil internacional?, ¿Cómo se dirimirá un conflicto de leyes y el domicilio de las partes contratantes cuya residencia está constituida en estados diferentes?, ¿Quiénes son los organismos encargados de ventilar y conocer de la causa?

Bajo ese contexto, una de las herramientas más antiguas y de tendencia armonizadora, la constituye la conocida Lex Mercatoria, cuya naturaleza jurídica es aplicable a las transacciones vinculadas a criterios de carácter geográfico, material y temporal, relacionadas y explicadas a lo interno de la misma.

No obstante, Calvo y Carrascosa (2004) aseveran que a través del tiempo, se han adoptado en lo que respecta a laudos arbitrales, diversas teorías jurídicas con relación a aplicación de normas internacionales, es decir:

"la teoría de la aplicabilidad de la Convención de Viena de 1980, como Lex Mercatoria, independientemente de que se presenten o no los factores indicados, al entender que en la medida en que la convención es el reflejo de las principales reglas del contrato de compraventa comunes a varios sistemas jurídicos, o de la costumbre internacional, resulta aplicable a los contratos internacionales" (Pag. 503).

Al respecto, otro de los rasgos incomunes del DUCI y de la gama de herramientas que fortifican el derecho de los negocios internacionales, la Convención de las Naciones Unidas para los Contratos de Compraventa Internacional de Mercaderías, acogida en Viena en el año de 1980, constituye uno de los principales instrumentos que más trascendencia ha tenido en lo que respecta al proceso de unificación y armonización del derecho comercial internacional

Históricamente y de acuerdo con Oviedo Albán (2010) la convención de Viena de 1980 es: "concebida como un intento de unificar la legislación aplicable a los contratos internacionales, es el resultado de una labor de varias décadas que se remontan incluso a las iniciativas finales del siglo XIX que produjeron como resultado: La Ley uniforme sobre ventas de Mercancías de 1905 de los países escandinavos, The sale of godos Act de 1983 de Gran Bretaña y, en la primera parte del siglo XX, el trabajo de la International Law Association, reunida en el año de 1924 en Estocolmo donde se trabajó en un proyecto de ley uniforme para la unificación de las legislación sobre compraventa internacional" (p.38)

Un aspecto determinante en cuanto a la utilización de la Convención de Viena es que ésta codifica únicamente, aspectos relativos a la formación de contrato y a los derechos del vendedor y comprador de mercaderías internacionales, no así, a la validez 0 efectos del contrato en conflicto.

En ese orden de idea, el ámbito de aplicación de la Convención adopta un carácter material y espacial al preceptuar que: "Artículo 1:

1) La presente Convención se aplicará a los contratos de compraventa de mercaderías entre partes que tengan sus establecimientos en Estados diferentes:

a) cuando esos Estados sean Estados Contratantes; 0

b) cuando las normas de derecho internacional privado prevean la aplicación de la ley de un Estado Contratante..."

En resumen, es indispensable que concurran ambos requisitos, y poder aplicar la Convención como exigencia sine quanon en el manejo de la misma, verbigracia: En caso de suscitarse un conflicto en un contrato de compraventa celebrado entre una compañía española y una compañía turca con establecimientos en sus respectivos países, de conformidad y en aplicación al artículo anterior, éste deberá regirse por la Convención de Viena de 1980, ya que los contratantes poseen sus establecimientos en distintos Estados que forman parte de la Convención.

Por su parte, los Principios UNIDROIT o PCCI, conforma otro 
de los instrumentos vanguardista utilizado para uniformar el derecho substantivo aplicable a contratos mercantiles internacionales y parte integrante de las normas integrantes del derecho uniforme del comercio internacional.

Según Perales Viscasillas, dichos principios poseen un aplicación arbitral superior a la judicial, afirmando que: la aplicación arbitral de los $\mathrm{PCCl}$ resulta propiciada por otros factores: la amplia libertad de que gozan las partes en el arbitraje, por la inclinación natural de los árbitros a utilizar el derecho comparado en sus laudos. (Perales Viscasillas, 2007, p. 163)

Sin embargo, la aplicación de este compendio jurídico está condicionado en el preámbulo de los mismos al determinar que:

"Estos principios establecen reglas generales aplicables a los contratos comerciales internacionales".

"Ellos deberán aplicarse cuando las partes hayan acordado someter el contrato a sus disposiciones".

"Estos Principios pueden aplicarse cuando las partes hayan acordado que el contrato se rija por los 'principios generales del derecho', la 'lex mercatoria' o expresiones semejantes".

"Estos Principios pueden proporcionar una solución a un punto controvertido cuando no sea posible determinar cuál es la regla (rule) de derecho aplicable a dicho contrato".

"Estos Principios pueden ser utilizados para interpretar o suplementar textos internacionales de derecho uniforme".

"Estos Principios pueden servir de modelo para la legislación a nivel nacional o internacional".

Finalmente, dentro de la gama de usos y prácticas negociales, encontramos a los INCONTERMS 2000 y en materia de créditos documentarios los RUU 500, los cuales fueron establecidos por la Cámara de Comercio Internacional, con el propósito de establecer precedentes contractuales para satisfacer lagunas existentes en un contrato sometido a interpretación.

Ortiz y Perales (2003) consideran que ambas prácticas se aplican a:

...un contrato si así se conviene expresamente por las partes, en forma un tanto condensada ciertamente en el caso de las RUU, y, desde luego, cualquier contrato de compraventa o de apertura de crédito documentario puede convenirse por las partes estableciendo una ad hoc disciplina convencional al mismo (p. 39)

Sin duda, un aspecto determinante en estos últimos, es la libertad que poseen las partes para determinar la disciplina y ley aplicable a un contrato específico (Principio de Libertad de Contratación). 
A fin de obtener un esquema jurídico de leyes, acuerdos y convenciones tendientes a armonizar las normas integrantes del derecho uniforme del comercio internacional, se elabora el siguiente diagrama sistematizado de modelos estatutarios aplicados universalmente.

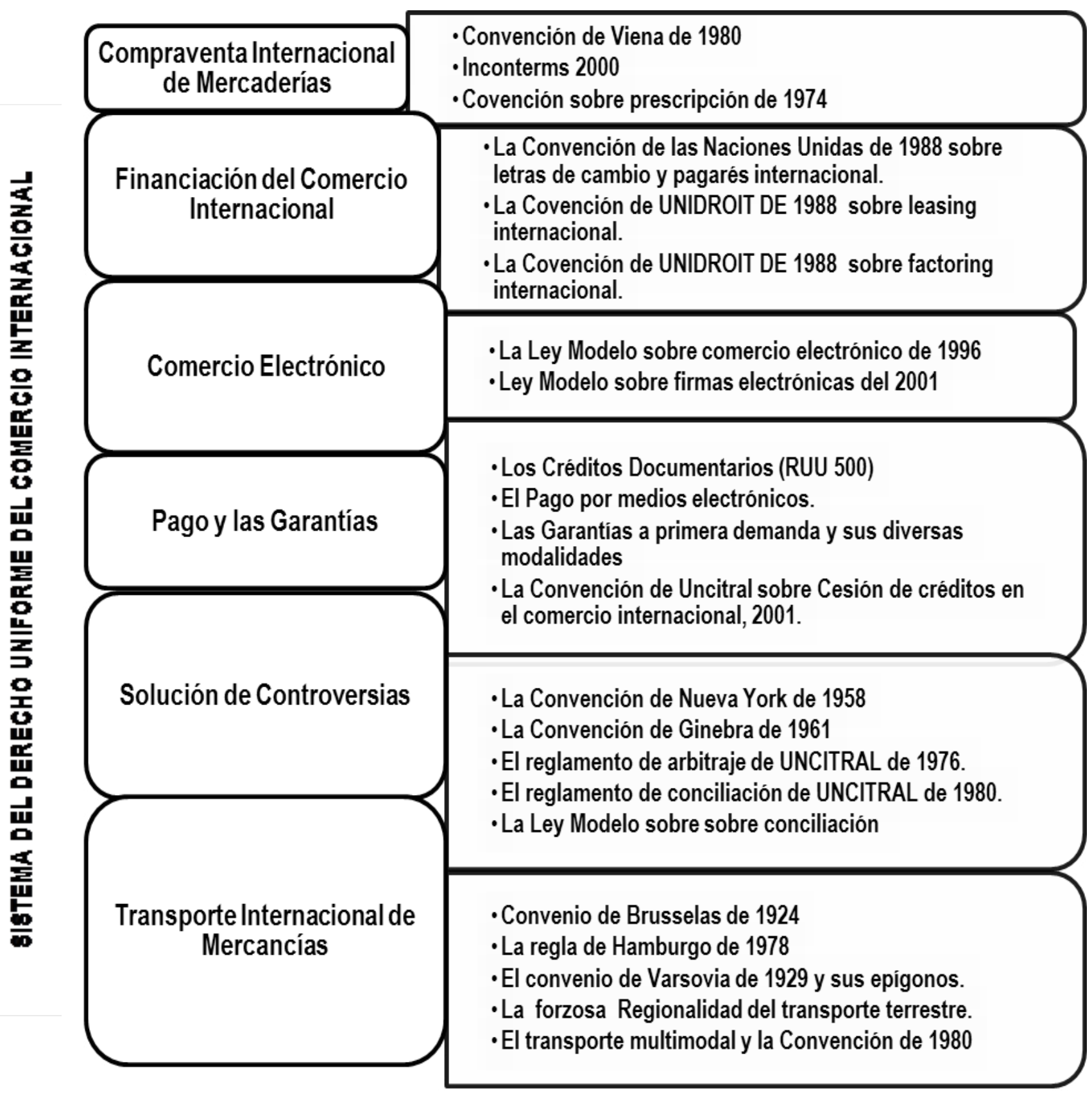

\footnotetext{
* Grafico elaborado con ideas propias, contenido extraído desde Ortiz Rafael Illezcas y Viscasillas Pilar Perales (2003), Derecho Mercantil Internacional, El Derecho Uniforme, España, Editorial Centro de estudios Ramón Areces S.A.
} 


\section{CONCLUSIONES}

- Ante la internacionalización privatista de la normativa jurídica internacional, ha existido siempre una clara necesidad de armonizar y uniformar las normas que integran el derecho mercantil y el derecho de los contratos y negocios internacionales

- En consecuencia, el origen del Derecho Mercantil Internacional se encuentra inspirado en acuerdos, tratados o convenciones multilaterales, los cuales son adoptados producto de una convención, cumbre presidencial o pactos comunitarios, las diferencias y conflictos que se suscitan entre los nacionales de esos estados se dirimen a través del Derecho internacional privado.

- Las normas integrantes o fuentes de producción jurídica comercial, están encaminadas a unificar y armonizar el comercio internacional entre los estados, cuyos reclamos y demandas se hacen evidentes ante la celebración de variados y múltiples contratos y de negocios comerciales internacionales.

- Bajo ese contexto, los organismos de carácter internacional han establecido un compendio normativo tendiente a disciplinar las relaciones comerciales entre los particulares de un estado cuya aplicación jurídica se encuentra determinada en cuanto a su naturaleza, ubicación y nacionalidad de las partes contratantes.

- Existe en la actualidad una ley específica aplicable a un caso concreto, es decir, la Convención de Viena ésta orientada a dirimir aspectos relativos a la formación del contrato y a los derechos del vendedor y comprador de mercaderías internacionales, no así, a la validez 0 efectos del contrato en conflicto. Asimismo los principios UNIDROIT, tienden a proporcionar una solución a un punto controvertido ante la imposibilidad para determinar la regla aplicable a un contrato determinado, los INCOTERMS por su parte, establecen reglas y usos en materia de créditos documentarios utilizados en transacciones internacionales.

\section{BIBLIOGRAFÍA}

1. Arroyo Fernández, Diego P. (2010), ¿Cómo se codifica hoy el derecho comercial internacional? Argentina, editorial Basedow.

2. Calvo Alfonso Luis y Carrascosa Javier (2004). Derecho Internacional Privado. Comares. $5^{\circ}$ Edición, 12 , Granada, España, Página 503.

3. Fernández Rosas José Carlos, Arenas García Rafael, De Miguel Asensio Pedro Alberto (2009), Derecho de los Negocios Internacionales, segunda edición, editorial lustel, Madrid.

4. Fernández de la Gándara, Luis y Calvo Carava, Luis Alfonso (1995), Derecho mercantil internacional, Estudios sobre Derecho comunitario y del comercio internacional, Madrid, Editorial Tecnos, S.A.

5. Foro de Derecho Mercantil, Revista Internacional $N^{0}$ 29,2010, Legis Editores, Puntos de vista Dr. Jorge Oviedo Albán, La Convención sobre Compraventa Internacional de Mercaderías , Pagina 38.

6. Kleinheisterkamp Jan (2009), Los principios Unidroit en la Interpretación del Derecho Nacional, España, Dykinson editores, Paginas 176-177.

7. Ortiz Rafael Illezcas y Viscasillas Pilar Perales (2003), Derecho Mercantil Internacional, El Derecho Uniforme, España, Editorial Centro de estudios Ramón Areces S.A.

8. Viscasillas, Pilar Perales (2007), Principios de Derecho Contractual Europeo y Principios de Unidroit sobre Contratos Comerciales Internacionales, Dikinson S. L, Paginas 156-157. 